\title{
In memoriam Wulf Koepke (1928-2010)
}

Am 14. Mai 2010 ist Wulf Koepke, der langjährige Mitherausgeber des Jahrbuchs Exilforschung, in Boston gestorben. Nach Studien in Freiburg und Paris, die er 1955 mit der Promotion abschloss, arbeitete Wulf Koepke für den DAAD in Singapur, anschließend am Goethe-Institut in München. Danach ging er als Hochschullehrer in die USA - an die University of Illinois (Chicago), die Rice University (Houston) und schließlich an die Texas A\&M University. Nach seiner Pensionierung lebte und forschte er als Distinguished Professor Emeritus in Boston. Zu seinen Forschungsschwerpunkten zählte außer dem Exil die Literatur der Goethezeit: Neben Büchern über Alfred Döblin und Lion Feuchtwanger hat Wulf Koepke Untersuchungen zu Johann Gottfried Herder und Jean Paul veröffentlicht. Wulf Koepke war zugleich Forscher und engagierter Pädagoge - wichtig waren ihm vor allem seine Studenten, die Leser seiner Bücher und zahlreichen Aufsätze, schließlich die Freunde und Kollegen, mit denen er auf Tagungen und Kongressen im germanistischen Universum zusammentraf und diskutierte. Seine letzte Arbeit, im diesjährigen Jahrbuch veröffentlicht, galt nicht zufällig Heinrich Mann - einem Autor, mit dem ihn nicht nur die gemeinsame Geburtsstadt Lübeck und die Erfahrung der USA verband, sondern vor allem auch die Überzeugung von der humanisierenden, bildenden und verändernden Kraft der Kultur. Wissenschaft und Leben, Literatur und Erinnerung standen für Wulf Koepke in unmittelbarer, enger Beziehung. Wie sehr sein Leben und seine wissenschaftliche Arbeit geprägt waren von der geschichtlichen und persönlichen Situation, die er vorfand und sich zu eigen machte, zeigt die Widmung seines letzten, 2008 erschienenen Buches Wartesaal-Jahre. Deutsche Schriftsteller im Exil nach 1933: "Gewidmet ist dieses Buch meiner Frau Monique, mit der ich seit 55 Jahren verbunden bin und deren Schicksal mir die Exilforschung als einen Brennpunkt meiner Arbeit vorgezeichnet hat, dem Andenken ihrer in Auschwitz ermordeten Eltern und besonders meinen Kindern und Enkeln, die in Amerika die hier geschilderte Erbschaft in ihrer eigenen Weise weitertragen." 
